\title{
Revolusi Industri 4.0 Dalam Penguatan Kesiapsiagaan Bencana Di Indonesia
}

\author{
Yuhdi Fahrimal, Muhammad Reza, Afrizal Tjoetra \\ Universitas Teuku Umar, Universitas Pakuan \\ Email : yuhdifahrimal@utu.ac.id, muhammadreza33@gmail.com, atjoetra@gmail.com \\ Jl. Alue Peunyareng, Kampus Universitas Teuku Umar, Ujong Tanoh Darat, Meureubo, \\ Kabupaten Aceh Barat, (0655) 77110535, 23681
}

Submitted: 02 August 2019 Revised: 08 October 2019 Accepted: 11 October 2019

\begin{abstract}
ABSTRAK
Paper ini bertujuan untuk melakukan penelahaan lebih lanjut mengenai peluang dan tantangan revolusi industri 4.0 dalam manajemen kesiapsiagaan bencana. Metode yang digunakan adalah kualitatif dengan menganalisis artikel yang didapatkan dari Google Scholar dengan kata kunci revolusi industri 4.0 dan kesiapsiagaan bencana. Hasil analisis terhadap dokumen terkait revolusi industri 4.0 didapati bahwa teknologi cloud computing, artificial intelligence, big data, dan internet of things berguna dalam mengumpulkan data, pemetaan, dan desain informasi risiko bencana secara real time dan up to date. Kondisi tersebut membuat manajemen penanggulangan bencana menjadi semakin efektif dan efisien karena data-data dihadirkan secara akurat sehingga meminimalisir kekeliruan atau distorsi data. Tantangan yang mungkin dihadapi dalam integrasi teknologi revolusi industri 4.0 dan manajemen kesiapsiagaan bencana turut dibahas.
\end{abstract}

Kata kunci: artificial intelligence, revolusi industri 4.0, kesiapsiagaan bencana

\section{ABSTRACT}

This paper aims to further examine the opportunities and challenges of the industrial revolution 4.0 in disaster preparedness management. The method used is qualitative by analyzing articles obtained from Google Scholar with keywords industrial revolution 4.0 and disaster preparedness. The results of an analysis of documents related to the industrial revolution 4.0 found that cloud computing technology, artificial intelligence, big data, and the internet of things are useful in collecting data, mapping, and design of disaster risk information in real time and up to date. These conditions make management of disaster management more effective and efficient because the data is presented accurately so as to minimize errors or data distortion. Challenges that may be faced in the integration of the industrial revolution 4.0 technology and disaster preparedness management are also discussed.

Keywords: artificial intelligence, disaster preparedness, industrial revolution 4.0

\section{PENDAHULUAN}

Bencana alam merupakan peristiwa yang sangat mengancam kehidupan manusia di dunia. Dalam beberapa tahun terakhir, peristiwa bencana alam sangat sering terjadi baik yang disebabkan oleh peristiwa geologi seperti gempa bumi, gunung meletus, dan tsunami, maupun kejadian bencana yang disebabkan oleh klimatologi dan hidrometerologi. Sawada dan Takasaki (2017) menyatakan bahwa negara berkembanglah yang mengalami dampak besar dari bencana karena peristiwa bencana dapat menyebabkan perekonomian negara lumpuh. Data EMDAT menunjukkan bahwa tujuh dari sepuluh negara dengan kejadian bencana paling sering terjadi adalah negara-negara berkembang seperti Indonesia, Afganistan, Filipina, dan Nigeria (Guha-Sapir, 2018). Menurut Boccard (2018) tren kejadian bencana alam yang melanda negara-negara di dunia dipengaruhi oleh beberapa faktor, 
yaitu, kondisi fisik wilayah serta kerentanan sosial, ekonomi, dan kultural.

Center for Research on the Epidemiology of Disasters (CRED) mengategorikan Indonesia sebagai satusatunya negara di kawasan Asia Tenggara dengan potensi tinggi bencana alam (Guha-Sapir et al. 2018). Berdasarkan laporan tahunan Badan Nasional Penanggulangan Bencana (BNPB) sepanjang tahun 2014-2017, telah terjadi 7.985 kejadian bencana alam meliputi banjir, angin puting beliung, gelombang pasang, gempa, dan tsunami. Bencanabencana tersebut mengakibatkan sekitar 1.725 jiwa menjadi korban meninggal dan hilang, lebih dari 10 juta jiwa mengungsi, dan sekitar 175.070 sarana pemukiman rusak parah dan ringan.

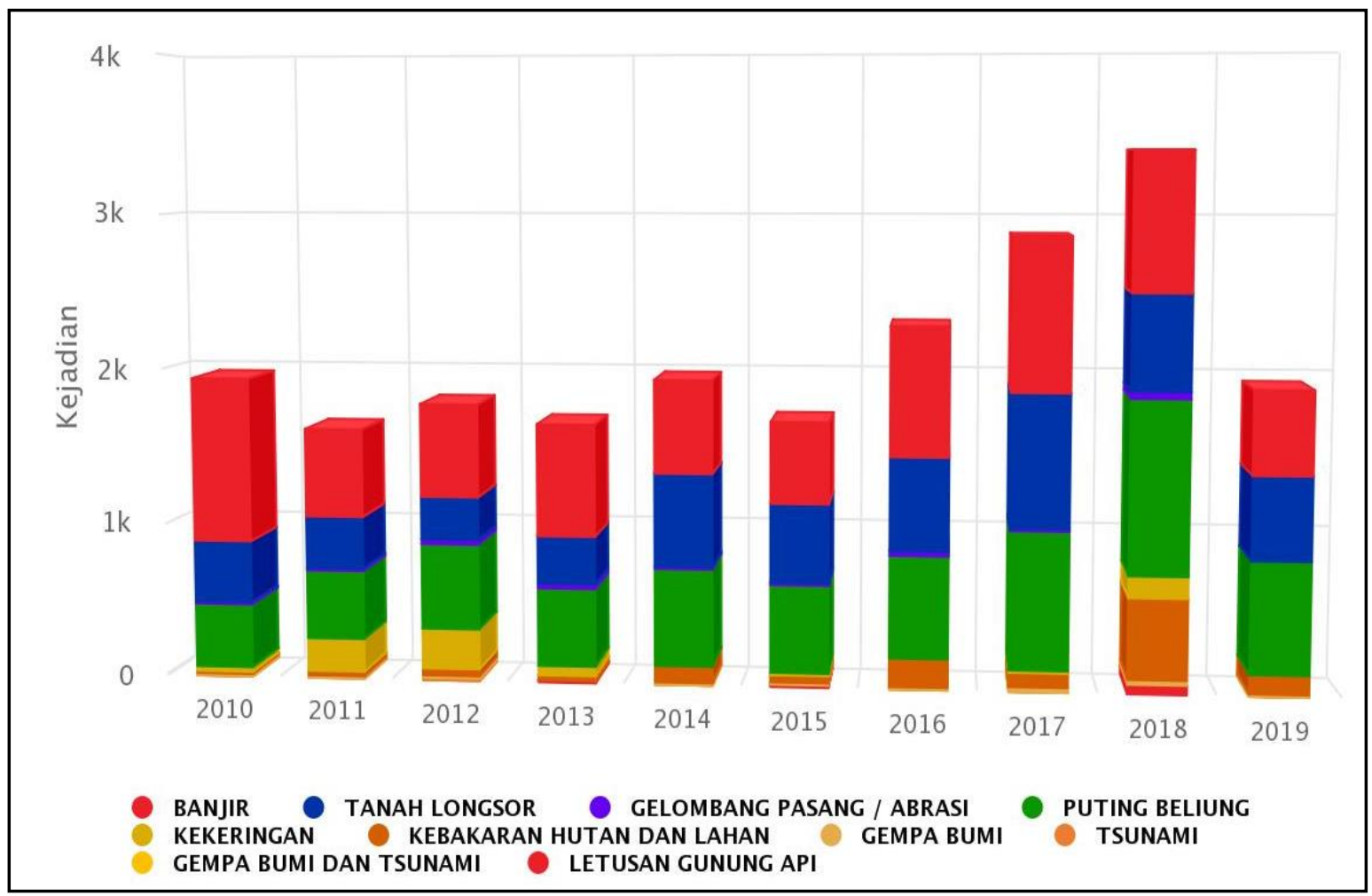

Sumber: DIBI BNPB

\section{Gambar 1 Data Tren Bencana di Indonesia 2010-2019}

Potensi risiko bencana yang tinggi di Indonesia disebabkan oleh dua kondisi, yaitu, (1) posisi geografis dan geologi Indonesia serta (2) kondisi kerentanan sosial ekonomi masyarakat. Secara geografis, Indonesia terletak pada pertemuan tiga lempeng tektonik, yaitu, lempeng Pasifik, lempeng Eurasia, dan lempeng Australia (Lassa, 2013; Djalante dan Garschagen, 2017). Tiga lempeng tektonik tersebut merupakan lempeng yang sangat aktif bergerak dan saling bertubrukan, sehingga wilayah-wilayah pesisir Indonesia berada dalam ancaman tsunami saat energi yang dilepaskan oleh lempeng tersebut terlalu besar. Selain itu, wilayah Indonesia juga memiliki sesar gempa nomor dua terpanjang di dunia setelah sesar San Andreas di Amerika bagian utara, yaitu, sepanjang $18.000 \mathrm{KM}$ (Stein \& Okal 2005).

Wilayah Indonesia juga dikelilingi lingkaran cincin api (ring of fire) dengan 127 gunung api aktif. Catatan historis 
mengenai kejadian bencana gunung berapi di Indonesia dapat dibaca dalam riset-riset para ilmuan seperti Chesner et al. (1991), Voight et al. (2000), dan Oppenheimer (2003). Dalam kurun waktu sepuluh tahun terakhir, beberapa gunung api di Indonesia mengalami erupsi dan menyebabkan korban jiwa dan kerugian harta bencana. Dua kejadian erupsi gunung merapi modern di Indonesia yang menjadi perhatian publik adalah erupsi Gunung Merapi di Yogyakarta tahun 2010 dan erupsi Gunung Sinabung di Karo Sumatera Utara tahun 2012.

Risiko bencana di Indonesia tidak hanya disebabkan oleh faktor geologis semata melainkan juga dampak dari kerentanan sosial dan ekonomi masyarakat. Saat ini pertumbuhan penduduk Indonesia sangat besar. Dalam data yang dipublikasikan Worldometers, pada tahun 2018 jumlah penduduk Indonesia adalah 265 juta jiwa dan menjadi negara dengan jumlah penduduk terbanyak ke-empat di dunia. Pertumbuhan populasi penduduk Indonesia diperkirakan akan mencapai 305,7 juta jiwa pada tahun 2035 (BPS, 2014). Mobilisasi dan pertumbuhan penduduk membuat kebutuhan terhadap lahan ikut meningkat dan berdampak pada pendirian bangunan di area rawan bencana -seperti pesisir dan wilayah sungai (Muis et al. 2015). Pembangunan yang serampangan tanpa memperhatikan aspek mitigasi bencana membuat kerentanan menjadi meningkat.

Penguatan kesiapsiagaan bencana menjadi aspek yang diperlukan saat ini dan masa depan. Bencana menjadi peristiwa yang sulit untuk diprediksi kedatangannya, sedangkan pengelolaan kesiapsiagaan yang hanya berbasis pada pendekatan pascabencana saja mulai kurang mendapat relevansinya (Djalante dan Thomalla, 2012). Kesiapsiagaan berkaitan dengan tindakan, kegiatan, komunikasi, dan koordinasi yang dilakukan seluruh sektor dan elemen untuk meningkatkan kapasitas publik menghadapi bencana. Kesiapsiagaan bencana menjadi fase paling menentukan dan berpengaruh besar dalam mengubah cara pikir dan cara tindak masyarakat di area rawan bencana (UNDP dan Kemendagri, 2012). Kesiapsiagaan bencana menjadi strategi fundamental untuk mereduksi atau mengurangi semua kerentanan baik fisik maupun sosial ekonomi (Maarif, 2010).

Kehadiran era revolusi industri 4.0 membuka peluang bagi pengembangan strategi baik struktural maupun nonstruktural untuk manajemen penanggulangan bencana khususnya di Indonesia. Gagasan pemanfaatan teknologi yang hadir dalam fase revolusi industri 4.0 ini diyakini dapat mereduksi beragam permasalahan yang selama ini dialami dalam manajemen penanggulangan bencana. Revolusi industri 4.0 yang berbasis teknologi informasi dan digital memberikan data dan informasi yang serba cepat, serba mudah, serba praktis, lebih efisien, dan berbiaya rendah namun jangkauannya juga sangat luas (Dahash et al, 2017).

Revolusi industri 4.0 muncul ketika manusia mencoba menghubungkan Internet of Things (IoT) dengan teknik manufaktur sehingga memungkinkan mereka mengumpulkan dan berbagi informasi, menganalisis, serta menggunakannya dalam protokol tindakan cerdas (Almada-Lobo, 2015; Rennung et al, 2016). Implikasi mendasar dari kehadiran revolusi industri 4.0 adalah mulai digunakannya berbagai hal yang 
berkaitan dengan teknologi komunikasi dan informasi serta teknologi digital dalam seluruh aspek kehidupan manusia, seperti, cyber-physical sustems (CPS), cloud technologies, Internet of Things (IoT), dan Internet of Services. Gagasan revolusi industri 4.0 merupakan perkembangan lanjutan dari revolusi industri pada era sebelumnya, dimana penggunaan teknologi komputer mempraktiskan cara kerja manusia.

Revolusi Industri ini juga menciptakan 1001 sensor baru untuk memanfaatkan informasi dan merekamnya setiap detik. Informasi yang beragam dari berbagai sumber yang berbeda mampu dikumpulkan secara up to date. Selanjutnya data itu dirangkum dalam bentuk Cloud Computing yang terhubung dengan internet (Truong, 2010). Semua perhitungan data tersebut bisa dikalkulasikan secara presisi (Lee et al., 2014). Machine Learning yang memiliki kemampuan untuk belajar secara otomatis dapat membantu dalam mengolah dan menganalisis segala informasi sehingga mampu melakukan koreksi dan prediksi yang tepat untuk memperbaiki hasil berikutnya. Hal ini bisa dikatakan dengan sebutan Artificial Inteligence.

Penelitian-penelitian terdahulu menunjukkan adanya peluang besar yang dibawa oleh revolusi industri 4.0 dalam bidang penanggulangan bencana. Riset Kang (2017) mendapati bahwa analisis terhadap big data dan kecerdasan buatan (artificial intelligence) dapat dimaksimalkan dalam pengembangan strategi penanggulangan bencana untuk meminimalkan kerusakan sosial, ekonomi dan lingkungan dari bencana. Riset Schwertner et al. (2018) memperlihatkan pentingnya integrasi antara perangkat mobile dan sensor, teknologi cloud, dan sistem informasi geografi diperlukan guna memberikan informasi dan data yang akurat terkait risiko dan potensi bencana. Riset Fang et al. (2015) mendapati bahwa sistem informasi terintegrasi yang dihasilkan dari geo-informasi, sistem informasi geografi, global positioning system, Internet of Things (IoT), dan cloud services sangat efektif untuk memprediksi banjir sehingga dapat menjadi dasar pengambilan keputusan yang tepat dalam penanggulangan bencana. Demikian pula riset Zlatanova dan Fabbri (2009) yang memperlihatkan integrasi teknologi geographic information system dengan teknologi informasi dan komunikasi menyediakan pemetaan yang akurat terhadap risiko bencana masing-masing wilayah sehingga dapat mengefektifkan pendekatan dan pengambilan keputusan respon.

Paper ini bertujuan untuk menelaah lebih lanjut peluang revolusi industri 4.0 beserta inovasi yang mungkin dihadirkannya terhadap penguatan kesiapsiagaan bencana di masyarakat Indonesia. Sebagai negara dengan risiko bencana yang tinggi, sudah selayaknya kesiapsiagaan individu dan komunitas ditingkatkan. Terlebih aspek kesiapsiagaan masih menjadi tantangan yang dihadapi dalam penanggulangan bencana di Indonesia. Revolusi Industri 4.0 membuka peluang untuk memaksimalkan segala sumberdaya untuk menghadapi kesiapsiagaan demi tercapainya visi zero victim dalam penanggulangan bencana. Revolusi Industri 4.0 mampu memberikan sumbangsih positif dalam bentuk penerapan teknologi yang bersifat fleksibel, akurat, transparan, dan hemat biaya. 


\section{METODE PENELITIAN}

Metode yang digunakan dalam penelitian ini adalah pendekatan kualitatif. Data-data dikumpulkan melalui penelaahan dokumen dari jurnal terkait dengan kata kunci revolusi industri 4.0, manajemen bencana, teknologi digital, internet of things, artificial intelligence, cloud computing, big data, drone, dan aspek-aspek lain yang terkait. Sumber utama artikel jurnal didapatkan dan dikumpulkan dari mesin pencari Google Scholar dengan mengetikkan kata kunci terkait. Selanjutnya peneliti melakukan pemilahan terhadap relevansi literatur yang ada. Pada tahap akhir peneliti mengelaborasi pembahasan berdasarkan literatur yang ada guna mengetahui peluang kehadiran revolusi industri 4.0 dalam manajemen kesiapsiagaan bencana di Indonesia.

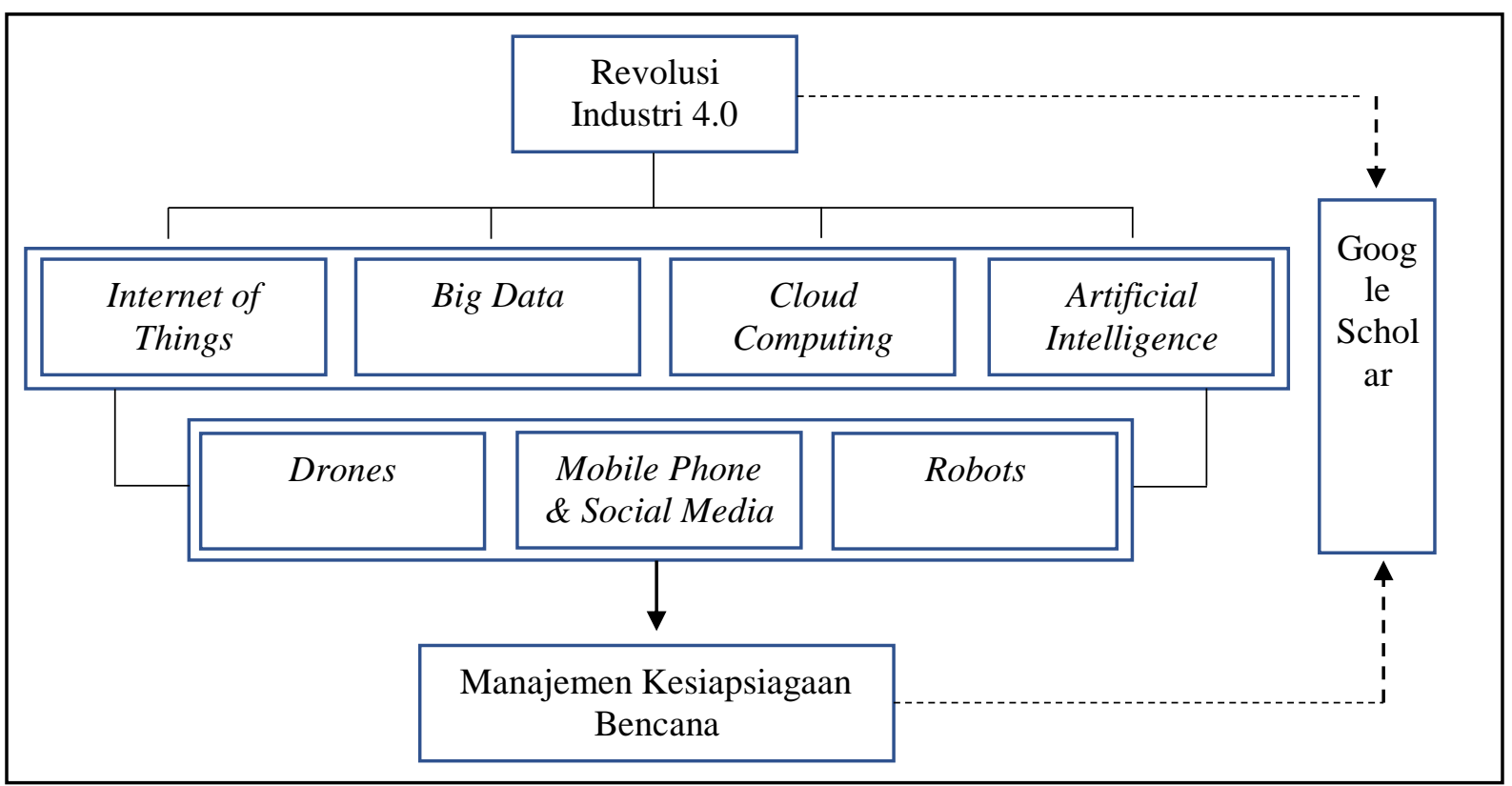

Gambar 2 Kerangka Penelitian

HASIL DAN PEMBAHASAN

Saat ini masyarakat dunia sedang bersiap memasuki era revolusi industri 4.0, yaitu, sebuah era dimana meningkatnya penggunaan teknologi digital sehingga berimplikasi terhadap berbagai sektor dalam kehidupan manusia (Drath dan Horch, 2014). Revolusi industri 4.0 merupakan kelanjutan dari era-era sebelumnya dimana penggunaan teknologi dan inovasi yang berkembang menjadi ciri dari setiap fase perkembangan tersebut (lihat Tabel 1). Tidak dapat dipungkiri bahwa revolusi industri 4.0 sebagai hasil dari perkembangan dalam bidang teknologi komunikasi dan informasi yang mengubah kebutuhan dan praktik interaksi sosial manusia (Prasetyo dan Sutopo, 2018). Sejak dicetuskan oleh Kanselir Jerman tahun 2011 dalam kegiatan Hannover Fair terminologi tersebut semakin sering digunakan dan dijadikan sebagai misi pencapaian masa depan pemerintah berbagai negara ( $\mathrm{Li}$ et al, 2017). 
Tabel 1 Perkembangan Revolusi Industri

\begin{tabular}{|c|c|c|l|}
\hline Fase & Fokus & Tahun & \multicolumn{1}{c|}{ Karakteristik } \\
\hline 1.0 & Manufaktur & 1780 & $\begin{array}{l}\text { Ditemukannya mesin uap sebagai pemicu industrialisasi } \\
\text { secara masif }\end{array}$ \\
\hline 2.0 & Teknologi & 1870 & $\begin{array}{l}\text { Inovasi Baja dalam skala masif dalam bentuk transportasi } \\
\text { dan jaringan rel kereta, dan mekanisasi listrik. }\end{array}$ \\
\hline 3.0 & Informasi & 1960 & $\begin{array}{l}\text { Komputerisasi dalam bidang aktivitas ekonomi, } \\
\text { Penggunaan teknologi informasi, Internet }\end{array}$ \\
\hline 4.0 & Digital & 2000 & $\begin{array}{l}\text { Penemuan dan pengembangan kecerdasan buatan, } \\
\text { nanoteknologi, Big data, mobile internet, computer } \\
\text { quantum, dan Internet of Things }\end{array}$ \\
\hline
\end{tabular}

Sumber: Schwab (2016)

Secara optimistik, revolusi industri 4.0 dipandang memberikan beragam manfaat. Revolusi industri 4.0 akan membuat pengambilan keputusan lebih transparan dan semakin terukur serta dapat diprediksi hasilnya karena dibantu oleh artificial intelligence yang mampu menghimpun berbagai macam informasi bahkan informasi yang sering sekali terbaikan namun berdampak penting. Revolusi industri 4.0 memungkinkan terciptanya sistem pengetahuan dimana setiap individu, peneliti, perguruan tinggi, pelaku inovasi, masyarakat, para profesional, dan para pemangku kepentingan dapat berkolaborasi untuk berbagi pengetahuan. Sistem seperti ini mampu menciptakan sistem yang terintegrasi terintegrasi sehingga menjadikan sistem tersebut lebih mudah untuk diakses dan murah (Pellini et al, 2018).

Menilik kejadian bencana alam yang sering terjadi di wilayah Indonesia, aspek manajemen bencana khususnya penguatan kesiapsiagaan penting untuk dikembangkan lebih lanjut. Terlebih dengan adanya peluang yang dihadirkan melalui revolusi industri 4.0 yang memberikan ruang bagi penggunaan Internet of Things (IoT), Cloud Computing, Mobile \& Social Technology, hingga penggunaan kecerdasan buatan
(Artificial Inteligence). Semua konsep dan inovasi tersebut dapat menggeser praktik manajemen risiko bencana yang konvensional dan tradisional yang selama ini masih digunakan oleh pemerintah dan penyelenggaran penanggulangan bencana di Indonesia.

Sakurai dan Murayama (2019) menyatakan bahwa teknologi digital memainkan peran penting dalam mencatat, bertukar, dan memproses informasi dalam sistem besar penanggulangan bencana. Sejalan dengan hal tersebut, Kryvasheyeu et al. (2016) memberikan pandangan optimis dari hadirnya teknologi dalam manajemen bencana. Peluang inovasi yang dihasilkan dari revolusi industri 4.0 memainkan peran penting dalam keseluruhan wacana manajemen bencana. Teknologi informasi digital tidak hanya berguna dalam masa tanggap darurat dan pasca-bencana saja, melainkan sangat berguna dalam fase pra-bencana khususnya dalam merancang strategi dan kerangka kesiapsiagaan bencana di masa depan.

Di tengah optimisme terhadap era revolusi industri 4.0 maka kelebihan tersebut berpeluang digunakan untuk pengembangan dan penguatan manajemen bencana khususnya aspek kesiapsiagaan (Schwertner et al, 2018). Teknologi cloud 
computing, artificial intelligence, dan internet of things berguna dalam mengumpulkan data, pemetaan, dan desain informasi risiko bencana secara real time dan up to date. Kondisi tersebut membuat manajemen penanggulangan bencana menjadi semakin efektif dan efisien karena data-data dihadirkan secara akurat sehingga meminimalisir kekeliruan atau distorsi data (Troy et al. 2008). Di sisi lain data-data yang akurat berguna untuk meningkatkan kepercayaan publik terhadap informasi bencana. Peningkatan kepercayaan terhadap informasi ini berkorelasi pula dengan keinginan masyarakat untuk mencari dan memperbarui informasi risiko, peningkatan kapasitas koping, serta mengefektifkan respon saat bencana terjadi.

\section{Geographic Information System} (GIS) merupakan salah satu bentuk awal dari pengaplikasian konsep cloud computing teknologi untuk memetakan suatu wilayah. Dalam manajemen bencana, aplikasi GIS telah banyak digunakan untuk pemetaan. Teknologi ini sangat berguna sebagai langkah antisipasi berbagai bencana alam yang telah terjadi untuk dipetakan lebih detail. Selanjutnya disimpan sebagai database untuk merencanakan sistem informasi geografis. Teknologi GIS yang semakin canggih dan terkoneksi dengan internet mampu membaca semua tipe data dalam bentuk: gambar, tabel, kondisi medan, dan grafik 3D secara real time karena dukungan sistem Big Data. Data tersebut tersedia dalam bentuk aplikasi yang memungkinkan data tersebut ditampilkan dalam bentuk permodelan visualisasi, dan melakukan analisis, termasuk ruang dan waktu (Schwertner, 2018). Visualisasi yang ditampilkan tersedia dalam bentuk infografis yang mudah untuk dibagikan secara online dalam berbagai platform media sebagai Baseline Data. GIS sebagai baseline data mampu menghimpun dan mengelola aliran data dan memprosesnya sehingga data yang di hasilkan merupakan hasil data yang sesuai dengan keadaan sebenarnya di lapangan. Sistem informasi yang dikembangkan dapat dianggap sebagai platform yang padu dan menjadi rujukan untuk melihat berbagai dampak yang di timbulkan bencana sebelum dan sesudah bencana itu terjadi.

Berdasarkan laporan yang dikeluarkan oleh International Telecommunication Union (ITU) sebuah lembaga di bawah Perserikatan BangsaBangsa (PBB) didapatkan gambaran besar mengenai penerapan teknologi digital dalam revolusi industri 4.0 di berbagai negara. Pasca-terjadinya gempa bumi yang menyebabkan meledaknya reactor nuklir Fukushima Daiichi pada 2011 membuat para ilmuan mengembangkan sistem robotik yang dilengkapi dengan kecerdasan buatan. Hal ini didasarkan pada pemikiran bahwa dalam situasi dimana penggunaan tenaga kerja manusia untuk melakukan pembersihan dan evakuasi tidak mungkin dilakukan, maka robot-robot cerdas dapat dimanfaatkan. Para ilmuan dari Universitas Tohoku dan perusahaan Honda mengembangkan sistem robotik yang diberikan teknologi artificial intelligence untuk melakukan mitigasi dan evakuasi saat terjadinya bencana. Beberapa robot yang telah diciptakan dengan teknologi kecerdasan buatan berupa robot ular dan anjing yang memiliki kamera kecil untuk memantau tingkat kerusakan bahkan mencari korban jiwa yang meninggal dan mungkin 
selamat. Di samping itu, robot tersebut juga dilengkapi dengan teknologi Global Positioning System (GPS) untuk memantau lokasi yang tepat dalam evakuasi korban jiwa (ITU, 2019).

Di Amerika Serikat penggunaan teknologi drone mulai dilakukan pascabadai Huricane Katrina tahun 2005. Saat itu drone digunakan untuk menyisir semua wilayah yang terdampak badai, mencari korban jiwa, memetakan situasi lingkungan, serta menilai dan menganalisis ketinggian banjir. Pada tahun 2018, badan penanggulangan bencana Amerika Serikat mulai menggunakan drone bawah air untuk mengukur panas lautan yang memicu badai dan mengirimkan datanya kepada National Weather Service (NWS). Data-data hasil pemetaan drone dimanfaatkan oleh para ahli untuk meningkatkan pemodelan badai melalui (1) prakiraan intensitas badai; prakiraan rute dan putaran badai; dan (3) mengukur salinitas untuk menentukan jumlah air dari hujan dan sungai yang bercampur di lautan (ITU, 2019).

Penggunaan drone dalam penanggulangan bencana juga diterapkan oleh pemerintah dan peneliti di Kepulauan Vanuatu. Drone udara digunakan untuk mengikuti arah Cyclone Pam guna menilai risiko dan potensi bencana yang mungkin ditimbulkan. Drone dianggap sebagai solusi ideal untuk evaluasi situasi yang cepat dan terperinci, terutama karena tutupan awan mengaburkan citra satelit. Gambar yang dipotret oleh drone dapat memetakan tingkat kerusakan rumah serta memandu upaya pemulihan pascabencana. Citra yang dihasilkan drone dimasukkan ke platform pemetaan sumber terbuka (open source) bagi sukarelawan untuk mengunggah dan memberi tanda posisi geografis pada gambar (ITU, 2019).

Di Pakistan telah dikembangkan sebuah sistem informasi yang memanfaatkan artificial intelligence untuk merespon saat bencana terjadi yang diberinama Artificial Intelligence for Disaster Response (AIDR). Sistem informasi ini berbasis microblogging yang mengintegrasikan data informasi dari media sosial seperti Twitter dengan partisipasi masyarakat sebagai prod-users informasi. Data dan informasi kejadian bencana, jangkauan destruktif, jumlah korban dan penduduk selamat, serta alokasi bantuan dapat dipetakan dengan baik dan real time. Tujuan AIDR adalah untuk mengklasifikasikan pesan yang diposkan orang selama bencana ke dalam sekumpulan kategori informasi yang ditentukan pengguna. Sistem AIDR telah diujicoba dan terbukti berfungsi dengan baik ketika bencana gempa bumi melanda Pakistan tahun 2013, dimana bantuan dapat disalurkan dengan cepat dan tepat setelah sistem informasi AIDR mengklasifikasi dan memverifikasi informasi dari para pengguna yang menjadi korban selamat secara cepat dan presisi (Imran et al, 2014).

Di Indonesia, bentuk penerapan revolusi industri 4.0 di bidang kebencanaan banyak mengadopsi konsep GIS sebagai baseline pemetaan yang telah digunakan oleh Badan Nasional Penanggulangan Bencana (BNPB). Institusi yang diberi kewenangan untuk melakukan penanggulangan dan pelaksanaan manajemen bencana di Indonesia tersebut telah membangun sebuah aplikasi yang dikenal sebagai InaRISK baik dalam bentuk laman inarisk.bnpb.go.id. atau pun dalam bentuk 
aplikasi mobile phone. Aplikasi InaRISK merupakan inovasi baru yang dikembangkan oleh BNPB bekerja sama dengan Badan Meterologi Klimatologi dan Geofisika (BMKG), LAPAN, Kementerian Energi dan Sumber Daya Mineral, serta Kementerian Pekerjaan Umum dan
Perumahan

Rakyat.

Dalam perkembangannya, kementerian lain juga ikut berkontribusi dalam mengembangkan InaRISK melalui supply data dan pembaruan sistem agar lebih presisi dalam menyajikan data risiko bencana di Indonesia.

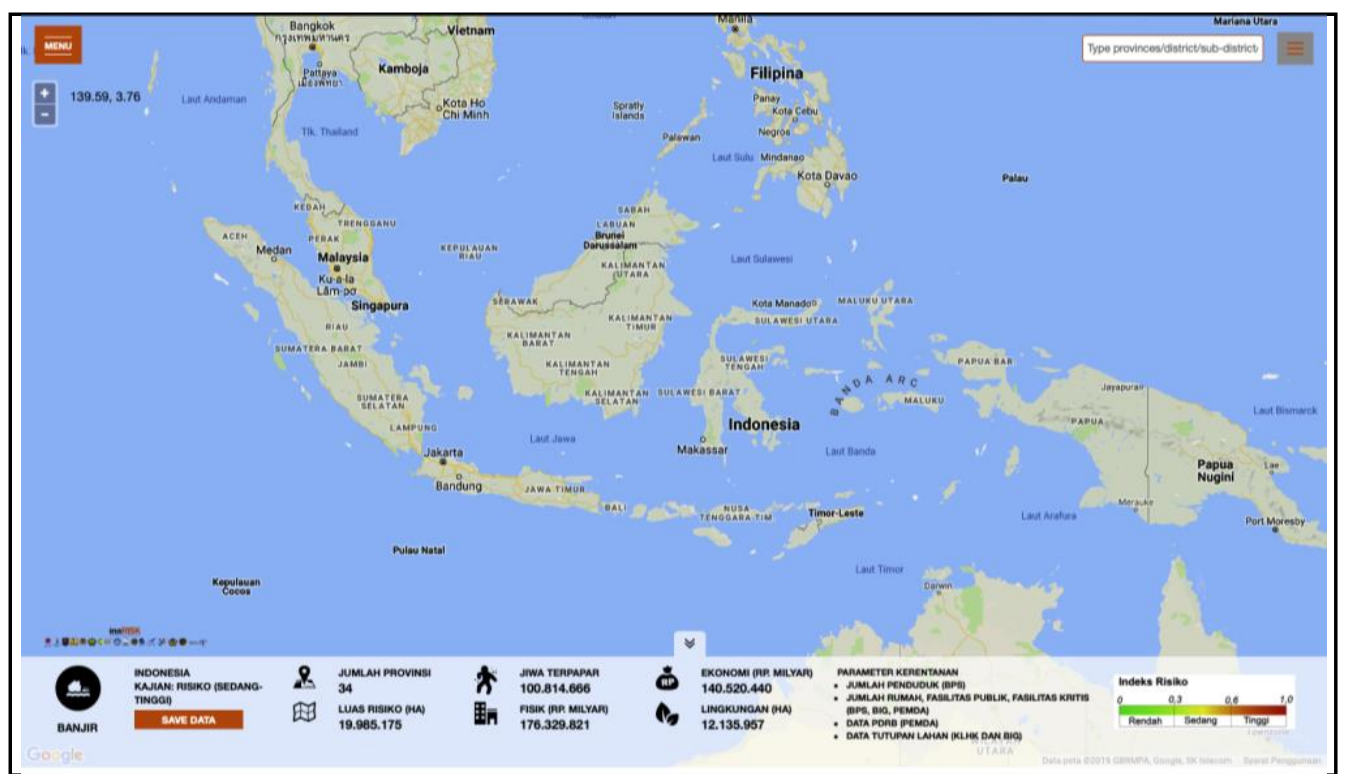

Sumber : inarisk.bnpb.go.id

Gambar 3 Contoh Halaman Pada Inarisk BNPB Untuk Bencana Banjir

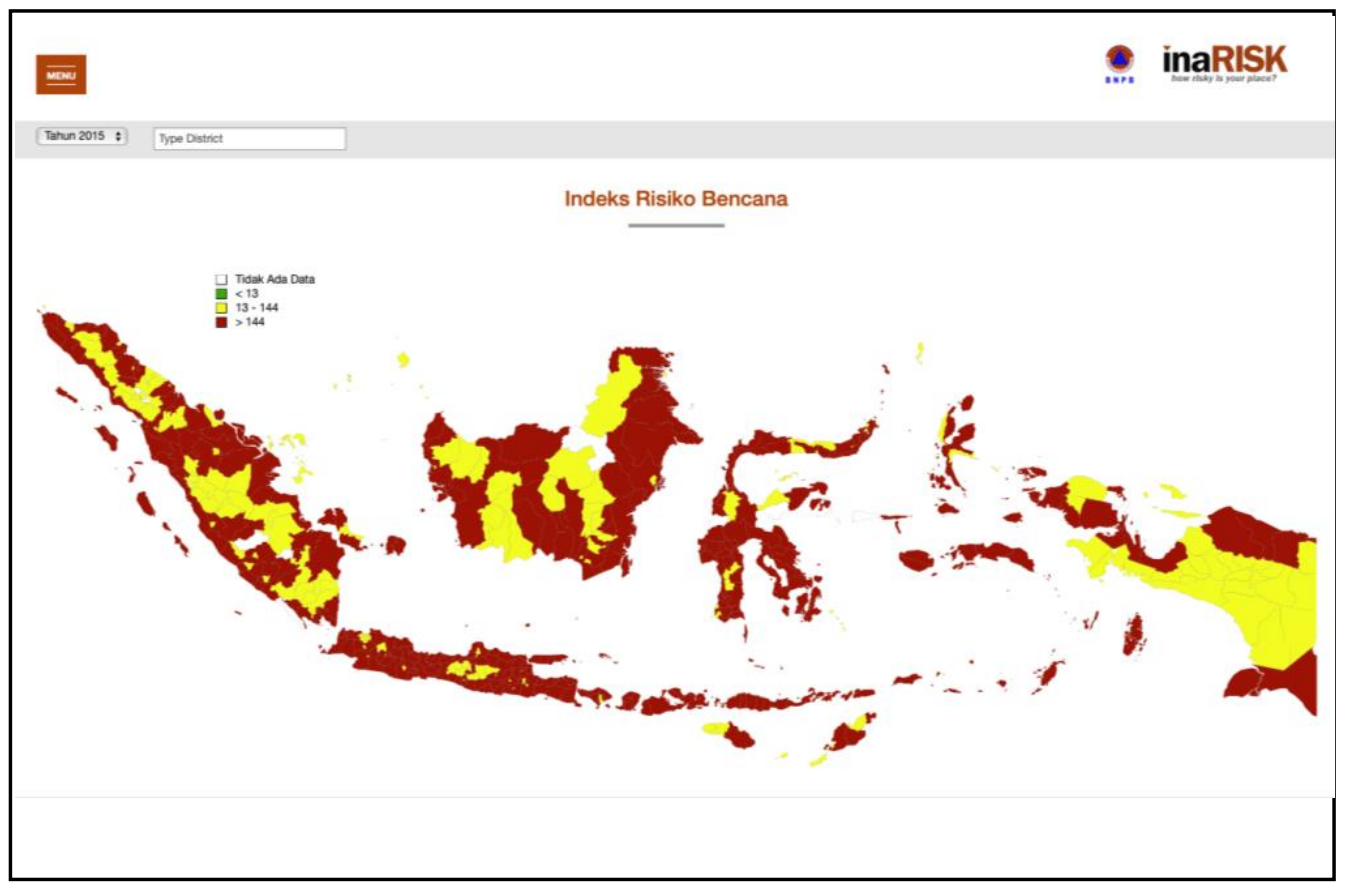

Sumber : inarisk.bnpb.go.id

Gambar 4 Peta Risiko Bencana di Inarisk BNPB 
InaRisk merupakan inovasi dalam manajemen bencana yang mengintegrasikan teknologi digital, geographic information system, dan internet of things dalam operasionalisasinya. Data dan informasi mulai dari risiko dan kejadian bencana tersedia secara real time dan diperbarui setiap saat. Paltform InaRisk menyediakan beragam informasi seperti jenis bencana di tiap-tiap daerah, peta bencana, infografis kerentanan dan risiko, ancaman dan bahaya bencana, kapasitas pemerintah daerah dan penduduk, serta data-data kependudukan dan wilayah lainnya yang terkait erat dengan kebencanaan. Data dan informasi yang tersedia dalam InaRisk tidak hanya bersifat nasional melainkan sampai pada tingkat kabupaten dan kota.

Sistem InaRisk dapat berguna dalam memperkuat kesiapsiagaan bencana khususnya aspek pengetahuan masyarakat terkait risiko bencana dan sistem peringatan dini (early warning system). Melalui data dan informasi yang tersedia dalam InaRisk, pengetahuan masyarakat terhadap risiko yang ada di sekitar mereka dapat ditingkatkan. Pengetahuan bencana berhubungan dengan tingkat kesadaran. Ketika masyarakat memiliki pengetahuan yang cukup terhadap suatu fenomena maka kesiapan menghadapi bencana dan strategi bertahan pasca-bencana dapat ditingkatkan (Troy et al, 2008). Di sisi lain, InaRisk juga dapat difungsikan sebagai sistem peringatan dini dimana InaRisk juga turut menyediakan cara pencegahan dan langkah penyelamatan yang harus dilakukan oleh masyarakat ketika berada di wilayah yang memiliki potensi bencana.

Meskipun perlu diakui bahwa kebutuhan informasi bencana di masa depan tidak cukup hanya sampai tingkat kota dan kabupaten saja melainkan harus sampai ke tingkat desa. Pemetaan dan informasi risiko bencana di tingkat desa perlu dihimpun dan disediakan karena bencana lebih banyak mengancam penduduk desa dan rumah tangga. Penduduk-penduduk di wilayah desa sering tidak memiliki pengetahuan yang cukup terkait bencana sehingga kesiapan mereka menghadapi bencana dan keluar dari situasi sulit saat bencana terjadi sering tidak maksimal. Dalam posisi ini keterlibatan pemangku kepentingan di tingkat daerah baik pemerintah daerah, Badan Penanggulangan Bencana Daerah, masyarakat, dan para relawan bencana sangat besar dalam menyediakan informasi ke dalam sistem besar InaRisk.

Optimisme terhadap teknologi digital yang menjadi pondasi revolusi industri 4.0 bukan tanpa tantangan. Beberapa tantangan penggunaan teknologi digital di era revolusi industri 4.0 dalam penanggulangan bencana, yaitu, pertama keahlian (skills), aspek ini berkaitan dengan kemampuan dan keahlian yang dimiliki manusia dalam penerapan teknologi digital. Kehadiran teknologi digital yang dibawa oleh revolusi industri 4.0 mendorong manusia untuk memiliki keahlian tertentu untuk mengoperasikan, memelihara, dan mendiseminasikan informasi yang tersedia. (ITU, 2019). Kedua, banjir data (data deluge), aspek ini berkaitan dengan melimpahnya data dan informasi yang dihasilkan oleh teknologi digital sehingga membuat sulitnya memilah dan memilih informasi yang sesuai kebutuhan. Ketika bencana terjadi, data yang ada dalam big data berada dalam jumlah yang banyak sehingga menjadi tantangan dalam manajemen, analisis, dan verifikasi data. Semua data 
yang ada tidak serta merta menjadi informasi yang relevan dengan kebutuhan, ketika hal tersebut terjadi maka respon menjadi kurang akurat.

Ketiga, informasi yang keliru (false information), bukan hanya kelimpahan data yang membuat respon bencana menjadi terganggu, kekeliruan informasi juga menjadi tantangan lainnya dalam penanggulangan bencana. Kecepatan arus data yang disebarkan saat bencana terjadi membuat informasi sulit diverifikasi. Konsekuensi terburuk dari situasi ini adalah sedikitnya penduduk yang dapat dievakuasi serta sedikitnya nyawa yang dapat diselamatkan. Dalam setiap kejadian bencana banyak informasi-informasi tidak akurat dan palsu yang berseliweran di ruang publik. Ke-empat, konsekuensi hukum (legal ramification), kehadiran teknologi digital yang bersifat disruptif menuntut dilahirkannya berbagai produk hukum yang baru. Sistem regulasi tersebut berguna sebagai dasar hukum untuk mengoperasikan perangkat teknologi digital. Di samping itu, perlindungan terhadap data dan informasi bencana juga perlu diperhatikan terlebih data-data tersebut dapat diakses secara terbuka dan dipertukarkan dalam ruang besar yang tidak terbatas sehingga terkadang dapat memunculkan ketegangan dalam aspek hak intelektual (ITU, 2019).

Kelima, derajat (scale), beberapa teknologi yang dibawa oleh revolusi industri 4.0 telah berkembang dalam derajat yang sangat luas dengan menghadirkan solusi out of the box dan ekosistem pendukung. Oleh karenanya, sulit untuk benar-benar memastikan solusi apa yang paling tepat dalam yang dapat diterapkan dalam satu praktik tertentu. $\mathrm{Ke}$ enam, biaya (costs), biaya yang diperlukan untuk mengimplementasikan solusi digital bagi manajemen penanggulangan bencana bisa sangat tinggi. Beberapa teknologi digital memiliki biaya yang sangat mahal baik biaya untuk membeli perangkatnya maupun biaya yang diperlukan untuk menggaji sumber daya manusia yang mampu mengoperasionalkannya.

Ketujuh, kepemilikan (ownership), kepemilikan baik perangkat maupun data menjadi salah satu tantangan masa depan yang harus diperhatikan agar tidak terjadi ketegangan antara pemerintah dan lembaga non-pemerintah terkait penanggulangan bencana. Beberapa pemerintah negara-negara di dunia telah memiliki perangkat dan sumber daya manusia yang mampu mengoperasionalkan dan membaca data-data yang disediakan oleh big data. Kedelapan, kesiapan (readiness), aspek ini berkaitan dengan kesiapan setiap negara untuk benar-benar menerapkan sistem teknologi digital dalam penanggulangan bencana. Penting untuk disadari bahwa kemampuan masingmasing negara sangat terbatas, terlebih biaya yang dibutuhkan untuk memasukkan teknologi digital dalam manajemen bencana sangat besar. Di sisi lain disparitas sumber daya manusia juga sangat terlihat dalam hal kemamuan mereka mengakses, menggunakan, dan mengontrol teknologi digital (ITU, 2019).

\section{SIMPULAN}

Kemunculan era revolusi industri 4.0 telah membuka berbagai peluang dan tantangan dalam kehidupan masyarakat. Di satu sisi dampak disruptif dari revolusi industri 4.0 menanggalkan cara berpikir konvensional masyarakat, sehingga masyarakat dipaksa untuk segera beralih pada penggunaan teknologi digital secara 
massif. Di sisi lain, revolusi industri 4.0 menghadirkan kemajuan yang pesat dalam bidang teknologi digital yang ditengarai dapat membantu kehidupan manusia.

Dalam aspek manajemen bencana berdasarkan pembahasan yang telah dijelaskan sebelumnya bahwa revolusi industri 4.0 menyimpan potensi besar jika dimanfaatkan dengan baik dan benar untuk penguatan manajemen kesiapsiagaan bencana. Terlebih bagi Indonesia yang menyimpan risiko bencana tinggi, kehadiran teknologi digital menjadi penting untuk dimanfaatkan dalam meningkatkan kesadaran masyarakat serta mendidik masyarakat tentang cara bertahan saat bencana. Platform InaRisk merupakan salah satu terobosan yang mengintegrasikan teknologi digital ke dalam manajemen bencana. Informasi dan data bencana yang tersedia dalam InaRisk bersifat real time, terbuka, dan mudah diakses masyarakat. Beragamnya jumlah data yang terdapat dalam platform Inarisk ternyata masih menjadi tantangan untuk dipecahkan, agar data-data tersebut semakin familiar bagi masyarakat sehingga masyarakat dapat mendapatkan manfaat secara langsung dalam mengambil keputusan sebelum dan sesudah bencana terjadi.

Revolusi industri 4.0 secara garis besar masih dalam bentuk gagasan sehingga dapat memunculkan berbagai kemungkinan arah pengembangan. Manajemen resiko bencana yang tangible terkait erat dengan aspek informasi dan komunikasi dalam bentuk implementasi pada sumber daya manusia. Oleh karenanya, tantangan ke depan adalah efektifitas praktik komunikasi dari inovasi yang dihasilkan dari revolusi industri 4.0 dalam bidang kebencanaan agar dapat meningkatkan literasi bencana di masyarakat. Aplikasi yang real time dan berbasis data harus disampaikan dengan bahasa yang dapat dipahami masyarakat, sehingga dapat diterima dan diterapkan oleh masyarakat.

\section{UCAPAN TERIMA KASIH}

Penulis mengucapkan terima kasih kepada seluruh pihak yang terlibat dan telah membantu penyelesaian tulisan ini. Terima kasih kepada sivitas akademik FISIP Universitas Teuku Umar yang telah memberikan dukungan kepada tim penulis sehingga tulisan ini dapat diselesaikan dengan baik. Semoga tulisan ini dapat bermanfaat untuk kajian lebih lanjut.

\section{DAFTAR PUSTAKA}

Almada-Lobo, F. (2016). The Industry 4.0 Revolution and the Future of Manufacturing Execution Systems (MES). Journal of Innovation Management, 3(4), 16-21.

[BPS] Badan Pusat Statistik. 2014. Statistik Indonesia 2014. Jakarta: Badan Pusat Statistik.

Boccard, N. (2018). Natural Disasters Trends. Technical Report. SSRN.

Chesner, C., Rose, WI., Deino, AL., Drake, R., \& Westgate, JA. (1991). Eruptive history of Earth's largest Quaternary caldera (Toba, Indonesia) clarified. Geology, 19(3), 200-203.

Dahash, HF., Al-Shammaari, S., Kulatunga, U., \& Hardman, MD. (2017). Cloud Computing for Disaster Response Management Stemming from Terrorism in Iraq. Dalam 13th IPGRC 2017 Full Conference Proceeding. University of Salford. Hal: 295-306.

De Stefani, P. (2017). Using Social Media in Natural Disaster Management: a Human-rights Based Approach. Peace Human Rights Governance, 1(2). 
Djalante, R., \& Garschagen, M. (2017). A Review of Disaster Trend and Disaster Risk Governance in Indonesia: 19002015. Dalam Djalante, R., Garschagen, M., Thomalla, F., \& Shaw, R. (editor). Disaster Risk Reduction in Indonesia. Berlin: Springer.

Djalante, R., \& Thomalla, F. (2012). Disaster risk reduction and climate change adaptation in Indonesia: Institutional challenges and opportunities for integration. International Journal of Disaster Resilience in the Built Environment, 3(2), 166-180.

Drath, R., \& Horch, A. (2014). Industrie 4.0: Hit or hype?[industry forum]. IEEE industrial electronics magazine, $8(2)$, 56-58.

Fang, S., Xu, L., Zhu, Y., Liu, Y., Liu, Z., Pei, H., \& Zhang, H. (2015). An integrated information system for snowmelt flood early-warning based on internet of things. Information Systems Frontiers, 17(2), 321-335.

Guha-Sapir. (2018). Review of Disaster Events. Supplementary Information. Brussels: CRED.

Imran, M., Castillo, C., Lucas, J., Meier, P., \& Vieweg, S. (2014). AIDR: Artificial Intelligence for Disaster Response. Proceeding of the 23rd International Conference on World Wide Web. Hal: 159-162.

[ITU] International Telecommunication United. 2019. Disruptive Technologies and Their Use in Disaster Risk Reduction and Management. Geneva: International Telecommunication United (ITU).

Kang, HJ. (2017). A Study on Disaster Safety Management Policy using the 4th industrial revolution and ICBMS. Journal of Digital Contents Society, 18(6), 1213-1216.

Kryvasheyeu, Y., Chen, H., Obradovich, N., Moro, E., Van Hentenryck, P., Fowler,
J., \& Cebrian, M. (2016). Rapid Assessment of Disaster Damage Using Social Media Activity. Science Advances, 2(3), e1500779.

Lassa, JA. (2013). Disaster Policy Change in Indonesia 1930-2010: From Government to Governance? International Journal of Mass Emergencies \& Disasters, 31(2).

Lee, J., Kao, HA., \& Yang, S. (2014). Service innovation and smart analytics for industry 4.0 and big data environment. Procedia Cirp, 16, 3-8.

Li, G., Hou, Y., \& Wu, A. (2017). Fourth Industrial Revolution: technological drivers, impacts and coping methods. Chinese Geographical Science, 27(4), 626-637.

Maarif S. (2010). Bencana dan Penanggulangannya Tinjauan dari Aspek Sosiologis. Jurnal Dialog Penanggulangan Bencana, 1(1), 1-7.

Mileti DM. (1991). Disaster by Design: A Reassessment of Natural Hazards in the United States. Washington, DC (US): Joseph Henry Press.

Muis, S., Güneralp, B., Jongman, B., Aerts, JC., Ward, PJ. (2015). Flood Risk and Adaptation Strategies under Climate Change and Urban Expansion: A Probabilistic Analysis Using Global Data. Science of the Total Environment, 538, 445-457.

Oppenheimer, C. (2003). Climatic, environmental and human consequences of the largest known historic eruption: Tambora volcano (Indonesia) 1815. Progress in physical geography, 27(2), 230-259.

Pellini, A., Weyrauch, V., Malho, M., \& Carden, F. (2018). State Capability, Policy Making, and Fourth Industrial Revolution: Do Knowledge System Matter? Discussion Paper. Bangkok: UNESCO.

Prasetyo, H., \& Sutopo, W. (2018). Industri 4.0: Telaah Klasifikasi Aspek dan Arah 
Perkembangan Riset.J@ti Undip: Jurnal Teknik Industri, 13(1), 17-26.

Rennung, F., Luminosu, CT., \& Draghici, A. (2016). Service provision in the framework of Industry 4.0. ProcediaSocial and Behavioral Sciences, 221, 372-377.

Sakurai, M., \& Murayama, Y. (2019). Information technologies and disaster management-Benefits and issues. Progress in Disaster Science, 100012.

Sawada, Y., \& Takasaki, Y. (2017). Natural Disaster, Poverty, and Development: An Introduction. World Development, 94, 215.

Schwab, K. (2016). The Fourth Industrial Revolution. Geneva: World Economic Forum.

Schwertner, K., Zlateva, P., \& Velev, D. (2018). Digital Technologies of Industry 4.0 in Management of Natural Disasters. Dalam Proceedings of the 2nd International Conference on $E$ commerce, E-Business and EGovernment (pp. 95-99). ACM.

Stein, S., \& Okal, EA. (2005). Seismology: Speed and size of the Sumatra earthquake. Nature, 434(7033), 581.

Troy, DA., Carson, A., Vanderbeek, J., \& Hutton, A. (2008). Enhancing community-based disaster preparedness with information technology. Disasters, 32(1), 149-165.

Truong, D. (2010). How Cloud Computing Enhances Competitive Advantages: A Research Model for Small Businesses. The Business Review, Cambridge, 15(1), 59-65.

[UNDP] United Nation Development Programme dan [Kemendagri] Kementerian Dalam Negeri. (2012). Making Aceh Saver Through Disaster Risk Reduction in Development; Panduang Pengurangan Risiko Bencana Berbasis MAsyarakat. Jakarta (ID): Kementerian Dalam Negeri.
Voight, B., Constantine, EK., Siswowidjoyo, S., \& Torley, R. (2000). Historical eruptions of Merapi volcano, central Java, Indonesia, 1768-1998. Journal of Volcanology and Geothermal Research, 100(1-4), 69-138.

Wright, KB., \& Rains, SA. (2014). Weak Tie Support Preference and Preferred Coping Styles as Predictors of Perceived Credibility within Health-related Computer-mediated Support Groups. Health Communication, 29(3), 281-287.

Zlatanova, S., \& Fabbri, AG. (2009). Geo-ICT for risk and disaster management. Dalam Scholten, HJ., Velde, RVD, \& van Manen, N. (editor). Geospatial Technology and the Role of Location in Science. Dordrecht: Springer. Hal: 239266. 